\title{
THE MAXIM OF QUANTITY, HYPONYMY AND PRINCESS DIANA
}

\author{
Dennis Kurzon
}

\section{Introduction}

To avoid referring explicitly to a particular person or group of people, a speaker may use a more general expression; in doing this, the speaker is in effect violating the Gricean maxim of Quantity. However, in the given context, it may be obvious, to the hearer, and to the observer (Goffman's 'bystander'; 1981), whom the referring expression in fact refers to. In saying "those people", for example, a speaker may implicate a certain group of people whose identity may be derived from the context, or even implicate a certain person who is a member, and probably a prominent member, of that group. This violation of the maxim of Quantity, and the subsequent set of inferences the hearer needs to draw in order to arrive at the desired referent may be examined in terms of hyponymy. This hyponymy is only partially semantic, for the relationship among the terms may depend more on background knowledge and context than on linguistic knowledge which governs semantic hyponymy. One manifestation of this hyponymous relationship is the tendency to generalize, a phenomenon that will frequently be noted in the course of the following discussion.

The violation of the maxim of Quantity in terms of hyponymy will be illustrated in the following paper through an analysis of extracts from Princess Diana's interview on the BBC television programme "Panorama" on November 20, 1995. This interview was broadcast worldwide, and, as it was reported in the press (Times November 21, 1995), the TV audience reached record levels (over 200 million people). From the way Diana answered the questions it was quite clear that the questions were presented beforehand to allow her to prepare some answer or response to the topics brought up. She was careful in what she told the interviewer, not giving him all the information she had on hand unless pressed, and even then she proceeded with caution. Withholding information, and expecting the hearer to fill in the gaps if possible, is a violation of the maxim of Quantity, which would then require resort to implicatures to obtain as full a picture as possible. Of course, this assumes all along that the interviewee, Princess Diana, was cooperating with the interviewer, Martin Bashir. We may naturally suppose that her willingness to appear on public television, and in front of a vast television audience, is sufficient evidence of her wish to cooperate. If not, then the only conclusion we can reach is that she was pulling everybody's leg or leading the whole world up the garden path, or any other quaint English idiom that may fit the situation.

Assuming, then, that Diana's performance was cooperative, I would like to analyse several extracts of the interview to show how she violated the maxim of Quantity, what she implicated by these violations, and of course what the observer has to infer in order to understand the full meaning of what was said. Firstly, a 
reminder, although I doubt that one is really necessary, of Grice's maxim of Quantity:

Maxims of Quantity: Give the right amount of information -

a) Make your contribution as informative as is required.

b) Do not make your contribution more informative than is required.

(Grice 1975)

The general maxim, "give the right amount of information", is qualified in that what would be considered the right amount would be dictated by circumstances, since "as is required" and "than is required" should be seen as contextual constraints. It will be seen in the discussion below, moreover, that maxim violation may not only concern that of Quantity, but also the maxim of Relation.

\section{Analysis}

In the interview, Diana avoided calling an entire group of people, who are central to her story, by their name and more informative title. Here, I am referring to the British royal family. Martin Bashir's questions were explicit in their reference to the royal family, but Diana managed to generalize various references. Let us look at an example in the following extract from the interview in which Diana is talking about the bulimia she had suffered from for several years:

(1) B: Did you seek help from any other members of the royal family?

D: $\quad$ No. (1.4) ts you you have to know that when you have bulimia you are very ashamed of yourself (1.3) and you hate yourself so uhm and people think you're wasting food. So it does you don't discuss it with people, and the thing about bulimia is your weight always stays the same, whereas with anorexia you visibly shrink.

Diana answers the interviewer's question concerning help from the royal family with a plain "No", but after almost a second-and-a-half pause she volunteers more information. After all, interviews of this type are not sessions consisting of "yes-no" questions with by the minimum answer as the response, but requests for information that go far beyond the positive or negative answer.

In this extract, Diana seems to be searching for a way to generalize on two issues. Firstly, she tries to avoid stating explicitly that she suffered from bulimia herself; this is done by the use of the generic "you" in, for example, "when you have bulimia you are very ashamed of yourself". However, it is quite clear from the context that it is she who suffered. Secondly, she tries to get away from any direct reference to the royal family (which may be interpreted as a type of taboo, similar to that found in various societies in the world, against mentioning her in-laws). She then links the bulimia with the reaction of people around her, and it is this word "people" that violates the maxim of Quantity. The word "people" in normal discourse does include "members of the royal family" in a broad sense, but in the present context it can only be interpreted as "members of the royal family". We may ask, using some logical formulation, how we move from 
members of the royal family $\epsilon$ people

to

members of the royal family $=$ people.

Let us take hyponymy as a meaning (both semantic and pragmatic) relationship between the two terms, i.e. "people" includes "members of the royal family". This
may be shown in the following diagram

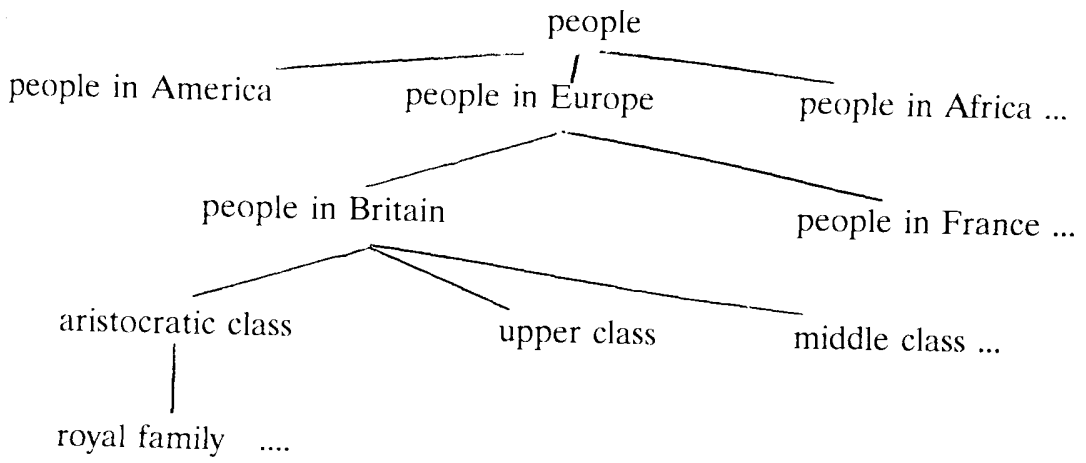

Figure 1.

The further one goes down the tree, the more, in this case, semantic features have to be added, i.e. more qualifications have to be used to restrict the reference and eventually to arrive at the group of people referred to. A speaker who does not use all the semantic features necessary to indicate the group of people intended is withholding some information. If so, then the maxim of Quantity may be measured in terms of semantic features. Of course, one should keep the context in mind, for very often contextualization makes it clear what the intended referent is. This accounts for the inclusion of pragmatic features in hyponymy where the context requires. The referent of the pronoun she in "She's just arrived", despite its generality, referring as it does to any female, may be understood in the context as old information, referring to a woman just mentioned, or as unused or evoked information (to use Prince's terminology, 1981), referring to a woman whose identity is known to the hearer from the more general context.

In the extract from the interview given above (1), Diana refers to this small group of people as "people" in general, hence this is a violation of the maxim of Quantity. Who are the people who think she is wasting food, and who are the people she will not discuss her problem with? Not, of course, people in general, or even people in Britain. The first part of the adjacency pair sets up the context, and Diana's answer is interpreted within this context.

Towards the end of the interview, Bashir attempts to make the Princess equate explicitly "people" with "the royal family" or even "the royal household": 
(2) D: People's agendas changed overnight. I was now separated, wife of the Prince of Wales, uh I was a problem, I was a liability, Iseen as, $\backslash$ and how are we going to deal with her? This hasn't happened before.

B: Who was asking these questions?

D: $\quad$ People around me, people in this environment, and

B: The royal household?

D: $\quad$ People in my environment, yes, yeah.

Again, Diana uses the superordinate term "people". She then goes on to "quote' them in "how are we going to deal with her?" in which "we" refers back to those "people". Bashir however wants the Princess to be explicit in her references, so she adds modifying locative expressions in "People around me", and "people in this environment", which add further semantic features to the hyponymous relationship set out diagrammatically, and minimally, in Figure 1 above. As a result, we now have, perhaps below "aristocratic class", a node labelled "people in this environment", assuming that not everybody who may be included in the aristocratic class is party to the goings on of the palace and of the royal family.

Bashir once again tries to get an explicit answer by suggesting a more defined group "the royal household", but all he receives in her response is a repetition of "people in my environment", i.e. people around Diana, followed however by "yes, yeah". This last part of her response may be read as agreement with Bashir's explicit description of the specific group "members of the royal household", which, by the way, is a more general group than "members of the royal family", since the more extensive group would contain officials and "highly placed persons" who are responsible for the running of the monarchy. Bashir does not labour the point. He interprets Diana's remarks as a reference to that taboo group by implicature, and he tries to obtain confirmation with regard to his interpretation from Diana, but does not completely succeed.

Not only is mention of the royal family as a group circumvented by Diana, but she also at times avoids mentioning the name of one particular member of that group - her husband Charles. One further step down the tree is found this member of the royal family and his name, although the question remains whether there is a hierarchical relationship among his name, his rank and his relationship with Diana. Do we simply have the following hyponymous relationship:

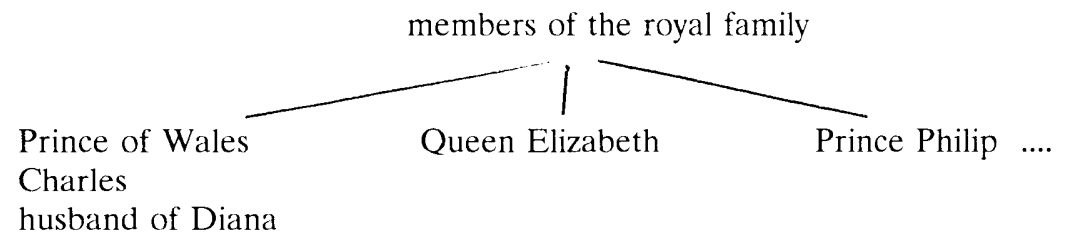

Figure 2.

or is there a more complex system in which "Prince of Wales" - the rank - is more important than the name "Charles", and the name is more important than his conjugal connection with the speaker, Diana? I will not answer this, not even define the word "important" in this context, but just regard these three terms as coreferential. 
Let us examine further extracts from the interview that present interesting data on the hyponymy present in these references. In the following extract (part of which I have deleted since it does not relate to the topic being discussed), Bashir asks Diana about Andrew Morton's biography of her which was published towards the end of 1992. After insisting that she had never spoken to the author, but allowed her friends to give him information, she was asked why she did so:

(3) D: I was at the end of my tether. I was (1.2) desperate. I think I was so fed up with being seen as someone who was a basket case, because I am a very strong person and I know that causes complications (0.8) in the system that I live in.

B: What effect do you think the book had on your husband and the royal family?

D: I think they were shocked and horrified and very disappointed.

B: $\quad$ Can you understand why?

D: (1.8) (Well) I think Mr Dimbleby's book was a shock to a lot of people and a disappointment as well.

B: What effect did Andrew Morton's book have on your relationship with the Prince of Wales?

D: (hhhh) (3.3) Well what had been hidden or or rather what we'd thought had been hidden then became (1.2) out out in the open and was spoken about on a daily basis and the pressure was for us to sort ourselves out in some way. Were we going to stay together or were we going to separate? and the word "separation" and "divorce" kept coming up in the media on a daily basis.

Firstly, we have a further general term "the system" which refers to the royal family or to the royal household in general, which Diana uses to avoid mentioning specific people or their ranks. Bashir, on the other hand, has no qualms about naming members of the royal family. Diana answers with a pronoun reference "they" in "they were shocked and horrified and very disappointed". She then does not answer Bashir's subsequent question concerning the shock and disappointment of members of the royal family, but she shifts the reference to other people in "a lot of people", and to another book - the journalist Jonathan Dimbleby's book on the Prince of Wales. Bashir then asks a specific question concerning her husband. Again, Diana does not answer by naming Charles or by referring to him by his title or his relationship to her ("my husband") but refers to him with her as team "we" (a fact she makes much of earlier in the interview).

We have a similar case in the following extract. Diana speaks of her husband's attitude towards her:

(4) D: I was always an embarrassment.

B: $\quad$ Do you think he really thought that?

D: $\quad$ (hhhh) (2.7) Well, there's no better way to dismantle a personality than to isolate it.

B: $\quad$ So you were isolated?

D: ((nodding)) Very much so. 
B: Do you think that Mrs. Parker Bowles was a factor in the breakdown of your marriage?

D: Well, there were three of us $(0.7)$ in this marriage, so it was a bit crowded. ((laugh))

When Bashir asks her to confirm Charles' attitude more explicitly, she again generalizes through her use of an existential sentence "there's no better way to dismantle a personality than to isolate it". This is a case similar to the generic "you" discussed in relation to extract 1 above; in that extract, Diana uses "you" to refer ostensibly to any bulimia sufferer, although implying herself. In the present extract, she utters an almost impersonal statement, but behind the verb "dismantle" is the dismantler, who is Charles according to the context, but Diana does not refer directly to him. Bashir continues with the impersonal approach by asking a question in the passive (for a fuller analysis of the use of the passive in generalizing see the discussion of extract (6) below). After Diana's affirmative answer, Bashir asks a very direct question about Mrs Parker Bowles, Charles' alleged girl-friend. The "we" of the previous extract, which refers to the team of Diana and Charles, has been expanded to include the other woman. Her allusion to the idiom "two's company [i.e. a team], three's a crowd" causes her to laugh.

In an earlier part of the interview, when Diana speaks of her self-inflicted injuries, the interviewer asked for some information concerning Charles' reaction to her behaviour:

(5) B: What was your husband's reaction to this when you began to injure yourself in this way?

D: Uhm. Well, I didn't actually always do it in front of him. Uhm but obviously anyone who loves someone will be very concerned about it.

B: Did he understand what was behind the physical act of hurting yourself, do you think?

D: No. But then there're not many people who would have taken the time to see that.

After a pair of verbalized hesitations or pause fillers ("uhm, well"), she refers to Charles by using the pronoun "him" whose textual reference is quite clear, but is far less explicit than naming the person or mentioning his relationship, etc. (Schiffrin 1994: 199ff). But then she begins to generalize by going up the tree using less semantic features, i.e. she does not give sufficient information (although one may always argue that the quantity of information is sufficient in the circumstances). This generalization is also produced hesitatingly by "uhm but" and "obviously". Her generalizations are pronoun equivalents of "people" and "a person" - "anyone" and "someone" - in "anyone who loves someone will be very concerned about it". This statement is ambiguous. Bashir's question concerns Charles' reaction, but she does not directly refer to this. Her statement using the pronouns could go two ways. As a positive answer to the question, one would include "my husband" within the reference of "anyone", and "someone" would refer to Diana herself. So, the meaning would be that Charles loves her so he was concerned about these self-inflicted injuries. On the other hand, it could also constitute a negative answer in that if 
Charles had loved Diana, he would have been concerned, but since he did not love her, then he did not react in the way loving husbands are supposed to.

This second interpretation seems to be supported by her answer to the next question. Again, she utters a "no" to the straightforward question about Charles' lack of understanding why she was injuring herself. She then generalizes again by stating that not many people (in the world?) would understand the situation; that her husband is included is the inference drawn from the utterance and from the context, this time, by way of the maxim of Relation. What seems to underlie Diana's answer is that only people who love the person who suffers would understand the situation. Charles does not understand the situation, therefore he does not love her.

Another way to avoid the mention of names is the passive form of the verb. In using the passive, the speaker suppresses "the fact that the agent is known" (Green 1989: 138); the agent then becomes an optional constituent in the sentence. So reference to the agent is only achieved by restoring what has been left out in the ellipsis. Martin Bashir asks:

(6) B:

The Prince of Wales, in the biography, is described as a great thinker, a man with a tremendous range of interests. (1.2) What did he think of your interests?

D: Well, I don't think I was allowed to have any. I think that (1.1) l've always been the eighteen-year-old girl (0.9) he got engaged to, so uh I don't think I've been given any credit for growth, (1.3) and my goodness, I've had to grow. ((laugh))

The question relates directly to Charles' opinion of Diana, but she does not explicitly attribute the stated opinions to Charles. She puts herself as subject of the clauses in her answer, and until the last remark ("I've had to grow"), each of the opinions are embedded in clauses depending on Diana's opinion, "I think" or "I don't think". In the first part of the answer "I don't think I was allowed to have any" the person who gives permission is not mentioned, and this is true for her third remark "I don't think I've been given any credit for growth", where the person who gives or does not give credit is not mentioned because of the passive. In both cases, Diana hesitates before she gives what seems on the surface to be an uncommitted answer. The second remark seems to attribute to herself the opinion of other people, or in the context set up by Bashir's question, her husband's opinion. This remark is elliptical in that what she leaves out may be included in the following interpretation: "I have always been thought of as being the eighteen-year-old girl he got engaged to". The "he" is of course Charles, but that may not be necessarily the person who has the opinions she lists. However, from the context provided by Bashir's question, we may derive the identity of the agent. The failure to mention her husband, even by a general pronoun or nominal substitute, constitutes a clear violation of the maxim of Quantity in that no information is explicitly given as to the identity of the holder of such opinions. By understanding Diana's implicature we arrive at the missing referent, Charles.

In the following extract from the interview being analyzed here, Bashir asks Diana about her post-natal depression after the birth of her first son:

(7) B: What effect did the depression have on your marriage? 
D: Well, it gave everybody a wonderful and new label. (?) "Diana is unstable" and "Diana is ehm mentally unbalanced". And unfortunately that seems to have stuck on and off over the years.

B: $\quad$ Are you saying that that label stuck within your marriage?

D: $\quad$ I think people used it (1.3) and it stuck, yes.

His question concerns her husband specifically, since he wants to know about the influence of the depression on their marriage, i.e. on her relationship with her husband. In her answer, we seem to have an enigmatic "everybody". From her husband, at the bottom-most node of the hierarchy we are looking at (Figure 2), she jumps a few nodes higher (in Figure 1). "Everybody" obviously does not refer to the whole world, but to the people in her environment, and in addition possibly to the people who follow the activities of the people in her environment - the press.

This generalization does not seem to answer the question; therefore, we could conclude that Diana was being uncooperative. But given the initial assumption that she agreed to the interview and was sincere in her agreement in that she will cooperate, the observer has to look for some relevance in her remarks. Although the focus of this discussion is on the maxim of Quantity and its violation, I do not discount violations of other maxims, especially that of Relation "Be relevant" (also see above in the discussion of extract (5)). Grice himself had doubts about the second maxim of Quantity: "Do not make your contribution more informative than is required." If someone is overinformative, s/he may be considered to be wasting time, possibly transgressing the Cooperative Principle. If cooperation is still being assumed, then the maxim of Relation may come into play to account for implicatures based on over-informativeness (1975: 46).

The problems with Diana's answer here are twofold: Firstly, it is a violation of the first maxim of Quantity which is not predicted to give way in favour of the maxim of Relation in Grice's scheme at least. Horn 1984's model, however, integrates both maxims; his speaker-based R-principle (which lays down that the speaker's contribution should be necessary and that the speaker should say no more than necessary; p.13), may show that everybody with its minimal content "may license the R-inference that [she] meant "more than [everybody]" (1984: 14). That is, "an $\mathrm{R}$-based inference renders the indefinite more informative than its logical form suggests" (p.15).

Secondly, it is not so clear what the connection is between what is happening inside the marriage (viz. "What effect did the depression have on your marriage") and the various labels that are attached to Diana. Later on in the interview, as we can see from extract (3) above, Diana does relate to the relationship between the couple as a result of Andrew Morton's book, but here, earlier on, she immediately generalizes. The label "that seems to have stuck on and off over the years" was used by "everybody", a set of people which does not necessarily include her husband. If her husband made use of a label, that need not become public knowledge. Terms of endearment between spouses are usually kept away from the ears of the public even if the couple are well-known, and the same may be expected with regard to terms of animosity.

Bashir does not give up, and asks the question in a more specific form with direct reference to "that label" and Diana's marriage. But yet again, Diana generalizes, and moves far above "my husband" (Figure 2) at which the question 
aims. "Everybody" in her first answer now becomes "people". Diana then seems to answer the question with her "it stuck, yes". This seems to imply that her husband made use of the label - of what people (her husband's family and circle?) said of her. So, the maxim of Quantity is being violated here, if Charles is included in "everybody" and "people", as with many of the examples already discussed. Moreover, there is an apparent violation of the maxim of Relation. The interpreter looks for a relevant connection between the questions and Diana's answers, and if the answers are relevant - and they are assumed to be if Diana is being cooperative - then it becomes quite clear that Charles did use these labels against his wife within the four walls of their house.

In the last extract to be analysed

(8) D: Uh, you know, the campaign was at that point was being successful, but it did surprise tho- the people who were causing the grief, it did surprise them when I took myself out of the game. They didn't expect that. Thn I'm a great believer that you should always confuse the enemy.

B: Who was the enemy?

D: $\quad$ Uhm (2.2) well. The enemy was my husband's department, because I always got more publicity. Uh, my work was mo mo was discussed much more than him. Uh, you know, from that point of view I can understand it...

Diana now replaces the fairly innoxious referring expressions to the royal household used up to this point by the noun phrase "the enemy". Her first mention of the enemy is, I believe, merely an idiomatic expression "to confuse the enemy" connoting in this context the difficulties she created for people interpreting her decision, but the interviewer does not let her off the hook. He asks for a denotation of the phrase "the enemy", which Diana then supplies after some hesitation. The other side, the establishment, is now called "my husband's department". On the one hand, she sees the enemy in the people surrounding her husband, and not her husband, but the phrase may also be interpreted, as it would be in most contexts, as the department that belongs to her husband. Such an interpretation leads one to see her opposing her husband and his camp, and not some nebulous establishment.

\section{Conclusion}

By way of conclusion, some simple numerical data would show the extent to which Diana did use substitute referring expressions for members of the royal family (Tables 1 and 2 below). References to a single individual, her husband Charles, could not be avoided as such, although she used his personal name only twice: references to Charles her husband 
$\begin{array}{cc}\text { references to Charles her husband } & \\ \text { by name ("Charles") } & 2 \\ \text { "my husband" } & 17 \\ \text { "the Prince of Wales" } & 2 \\ \text { others } & \frac{7}{28}\end{array}$

Table 1

but references to the Queen, the royal family and royal household, were far less explicit:

$\begin{array}{lr}\text { references to the Queen, etc. } & \\ \text { "Her Majesty" } & 1 \\ \text { "the Monarchy" } & 6 \\ \text { "the/this family" } & 3 \\ \text { "the environment" } & 3 \\ \text { "the system" } & 1 \\ \text { "people" } & 13 \\ \text { others } & \underline{20} \\ \end{array}$

Table 2

Apart from the telling phrase "confuse the enemy" in extract (8) above, Diana also lets it be known that she is "outside the net", and that is what has caused, and will keep on causing, her trouble. I leave it to the readers to suggest various connotations of "the net", which Diana, of course, does not elaborate on, violating as she does the maxim of Quantity.

The maxim of Quantity has been discussed in what are basically semantic terms, for hyponymy may be considered a fundamental semantic relationship in the same way as synonymy and antonymy are. But a perennial problem turns up, since it is apparent that many of the items on the trees in Figures 1 and 2 depend not on linguistic knowledge, which would then include semantic knowledge, but on world knowledge, of the type that is acquired over a long period of time, if at all, even if the speaker is a competent speaker of the language. That countries have people, or, possibly, that communities may be divided up into classes, or that queens have princes for sons may all be considered semantic knowledge, that is knowledge of the meanings of the various words and their interrelationships. If that were the case in all instances, then the maxim of Quantity would be reduced to a semantic principle. But knowledge of specific references such as "Charles", "the Queen", "people in my environment" is not semantic in nature, but is dependent on extralinguistic features. Hence, this type of hyponymy may be partially semantic, but to a larger degree it is pragmatic. 


\section{References}

Goffman, E. (1981) Forms of Talk. Oxford: Blackwell.

Green, G.M. (1989) Pragmatics and Natural Language Understanding. Hillsdale: Lawrence Erlbaum.

Grice, H.P. (1975) Logic and Conversation. In P. Cole \& J.L. Morgan (eds.), Syntax and Semantics III. New York: Academic Press, pp. 41-58.

Horn, L.R. (1984) Toward a new taxonomy for pragmatic inference: Q-based and R-based implicature. In Georgetown University Round Table on Languages and Linguistics. Ed. D. Schiffrin. Washington D.C.: Georgetown University Press, pp. 11-42.

Prince, E.F. (1981) Toward a taxonomy of given-new information. In P. Cole (ed.), Radical Pragmatics. New York: Academic Press, pp. 223-255.

Schiffrin, D. (1994) Approaches to Discourse. Oxford: Basil Blackwell. 